\title{
Analysis on the Dilemma of Management over County Cultural and Creative Industry in Our Country and its Solutions
}

\author{
Minkuo Zhang \\ Hunan International Business Vocational College, Changsha Hunan, 410200, China
}

Keywords: County, Cultural and creative industry, Dilemma, Solution.

\begin{abstract}
In recent years, as an emerging industry, the county cultural and creative industry has shown its powerful vitality in practice and has become an important industrial sector for economic growth and social development in all countries around the world. Strengthening the management over cultural and creative industry and better adjusting the chain layout of cultural and creative industry are very significant for promoting the sustainable development of county cultural and creative industry. This paper elaborated the general situation of development of county cultural and creative industry in our country, analyzed the dilemma of management over county cultural and creative industry in our country and put forward specific measures for solving the dilemma of county cultural and creative industry in our country, in the hope of better improving the management quality and level of China's county cultural and creative industry.
\end{abstract}

\section{Introduction}

Compared with the manufacturing industry in the traditional sense, the county cultural and creative industry is an industry with no pollution, high additional value and low energy consumption. The exploitation of cultural and creative industry can meet the county people's continuously increasing spiritual and cultural needs, so the county cultural and creative industry plays an increasingly important role in the comprehensive and coordinated development of economy. To promote the development of China's county cultural and creative industry, it is required to spare no efforts to excavate and utilize the historical and cultural resources in a county, especially inherit and develop the endangered intangible cultural heritage, combine the inheritance, innovation and development of China's excellent traditional culture with the development of county cultural and creative industry; besides, it is required to not only permeate county cultural resources into the cultural industry for development but also truly convert the advantages of cultural and creative resources into the huge advantages of industrial development. Practically enhancing the county creative cultural industry can comprehensively show its local characteristics and cultural characteristics [1] and manifest the charm of our country as a powerful cultural country.

\section{General situation of development of China's county cultural and creative industry}

The UK is the country which gave an official definition of creative industry at the earliest and came up with the concept of "creative industry" for the first time in the Creative Industries Mapping Document published in 1998. Although the creative industry came from the cultural industry, it is different from the cultural industry. The county economy has always been a basic part of China's national economy as well as a stabilizer for promoting the continuous development of China's economic society. With the transformation and upgrading of China's county economy and the implementation of the national new urbanization planning, how to dig out the cultural and creative elements in counties and activate the local vigor is extremely important for narrowing the urban-rural gap and driving the coordinated development of counties [2]. Over recent years, many counties or county-level cities in eastern China have been continuously integrating with other industries by virtue of their traditional technologies and cultural resources; thus, they have become classic cases for interinfiltration and fusion between China's cultural and creative industry and county economy. 


\section{Dilemma of management over China's cultural and creative industry}

China's county cultural and creative industry has a certain development scale. However, compared with the situation of development of county cultural and creative industry in western countries, the development of county cultural and creative industry in China still lags far behind. The dilemma of the development of China's county cultural and creative industry includes the following four aspects.

\section{The macro-management policies regarding county cultural and creative industry needs improving.}

At present, there is no unified and high-efficient mechanism of organization and management of county cultural and creative industry in China now. The high relevance of cultural and creative industry urges to realize coordinated development and unified management among various industries so as to better maintain the completeness and natural extension of county cultural and creative industry chain. As far as the reality is concerned, the barriers between the central government and local governments at all levels and between the department and industry still have not been broken and eliminated yet; the basic function of market resource allocation still cannot be exerted effectively. As a result, this has resulted in the insufficiently proper transformation of government's functions, hindered flow of information on county cultural and creative industry, fragile business startup guidance system for county cultural and creative industry and other practical problems, which have leaded to the failure to realize the commercialization of the achievements of cultural and creative industries and formed obstacle factors for the effective management over county cultural and creative industry.

The construction of laws and regulations concerning county cultural and creative industry needs to be strengthened urgently.

Since China's cultural field is always under the system of unity of management and operation, the management effect mainly needs to be realized with administrative measures and the construction of laws, regulations and systems is relatively lagging behind. Therefore, it's an arduous task to build a more perfect laws and regulations concerning county cultural and creative industry and form a more open, fair and just cultural and creative environment.

\section{The shaping of main market players of county cultural and creative industry needs to be strengthened urgently.}

At present, the ownership of main enterprise market players in the cultural and creative industry in some counties of China is not clear enough; there is usually no contributor for state-owned cultural assets; the ownership and right of management are separated from each other; it is difficult to effectively perfect the corporate legal person management system and the incentive and restraint system etc.; the behavioral subjects' segregation of duties is not distinct and the responsibilities are ambiguous; there is no public service system suitable for the reform in industrial subjects, resulting in large difficulty in the management over market subjects of the enterprises of county cultural and creative industry.

\section{The regional discrepancy of county cultural and creative industry needs to be narrowed.}

The development pattern of China's cultural and creative industry is generally the same with that of its overall economy; there is a significant difference between the eastern and western areas; the development degree is high in the eastern area and low in the western area. Regardless of the quantity of cultural and creative industry enterprises, number of practitioners, amount of assets owned and other aspects, the shares in the eastern region is considerably higher than those in the central and western regions. Once the regional imbalance during the development of county cultural and creative industry continuously increases, the imbalance in economic and social development between the eastern and western regions will be more prominent. How to change this situation has become an 
important strategic issue to be solved urgently by the cultural and creative industry parks and management departments.

\section{Analysis on countermeasures for the management dilemma of China's cultural and creative industry}

\section{To formulate and issue long-term planning to promote the development of county cultural and creative industry}

Based on the imbalance in the development of county cultural and creative industry as well as the different development situations and levels in different counties and cities, selectively list the development of cultural and creative industry into a county or city's development planning; determine the major cultural and creative industry to be supported and developed in this region according to the unique characteristics and brand advantages of different county cultural and creative industries; besides, formulate and issue the long-term development planning for cultural and creative industry of a later period [4] so as to point out the direction for the sound development of cultural and creative industry.

\section{To form the policy system, which promotes the development of county cultural and creative industry}

In order to facilitate the development of China's county cultural and creative industry, it is required to continuously intensify the degree of support and implementation of policies related to county cultural and creative industry and pay attention to energetically supporting the better development of county cultural and creative industry in project approval, land use, tax revenue, funds, credit, financing, import \& export, social security and related policies. Meanwhile, guide the aggregation and integrative development of capital, technology, information, talent and all sorts of resources in the county cultural and creative industry, and better emancipate and develop the productive force.

\section{To continuously increase the fund investment and implement related incentive policies}

Energetically support the development of county cultural and creative industry; especially support a group of county cultural and creative projects full of development potential. One the one hand, continuously intensify the fund investment, allocate funds the major county cultural and creative industry enterprises which are closely related to the cultural life of the masses, actively adjust the related financial policies, ceaselessly enhance the financial investment in county cultural and creative industry and designedly construct the major development projects of county cultural and creative industry in batches. On the other hand, the incentive policies formulated by government departments concerned on county cultural and creative industry should insist on the principle that investors gain benefits and actively mobilize the whole society to invest in the industry [5]. Meanwhile, make reasonable tax preference, reduction and exemption policies supporting the development of county cultural and creative industry, stimulate the vast masses' enthusiasm to develop county cultural and creative industry, strengthen the links among the government, enterprises and all non-governmental organizations, establish a more close cooperative relationship between the government and non-governmental organizations and continuously expand the sources of creativity for county cultural and creative industry so as to inject vigor for the sustainable development of China's county cultural and creative industry.

\section{To intensify the cultivation and introduction of talents for county cultural and creative industry}

Intensify the cultivation of professionals for county cultural and creative industry to provide powerful an intellectual support for the sound and sustainable development of county cultural and creative industry. Firstly, make great efforts to scout for professionals for county cultural and creative industry. Find out the potential cultural and creative talents hidden in the civil society by holding various 
cultural and creative design contests etc. Of course, it is also feasible to establish the employment agencies for professionals of county cultural and creative industry to take charge of deeply excavate county cultural and creative talents. Secondly, endeavor to cultivate professionals for county cultural and creative industry. If the condition allows, propel researches on county cultural and creative industry, provide specialties of cultural and creative industry in institutions of higher education of the local region and conduct professional learning of the management over county cultural and creative industry. Strengthen the mutual links between the local institutions of higher education and county cultural and creative industry enterprises so as to create favorable conditions for exertion of college students' creativity. Meanwhile, intensify international exchange and cooperation and continuously expand horizons to cultivate more high-quality cultural and creative professionals [6].

\section{To perfect the financing service system of county cultural and creative industry}

The small and medium-sized enterprises in China's county cultural and creative industry are the main bodies currently. Under this circumstance, it has a great financial risk to invest in such small and medium-sized enterprises engaged in cultural and creative businesses, so there are generally difficulties in the financing of cultural and creative enterprises. In view of this phenomenon, the following measures can be taken to improve the financing service system of county cultural and creative industry: firstly, continuously strengthen the guidance and policy coordination for the development of county cultural and creative industry. Secondly, standardize and develop intermediary service agencies. Thirdly, implement the financing service with asset securitization, a brand-new financing tool. The business secrets of county cultural and creative industry enterprises can be protected better by implementing the strategy of asset securitization, because the original originators only need to supply relevant information available for asset securitization in the process of asset securitization financing; this can greatly help to protect the business secrets of county cultural and creative industry and can also help such enterprises to compete with other ones.

\section{To intensify the protection of intellectual property of cultural and creative industry}

For better development, the county cultural and creative industry is in sore need of the support and protection from a sound and perfect legal system. Once the laws and regulations fail to come into play, the development of county cultural and creative industry will be severely affected. Among a series of legal systems regarding county cultural and creative industry, the intellectual property protection can be said to be the priority among priorities. In the information times, the modern information technology brings a great challenge for intellectual property protection. Once the society begins to respect and acknowledge individuals' values of creativity, a first-class environment to acknowledge and protect the originality of products will be generated. As far as the government department is concerned, it is required to raise the intellectual property protection to the height of strategy and thus form an environment to protect and respect individual works and creativity. Thus, it requires us to make and implement strategies concerning intellectual property as soon as possible, perfect and improve reasonable laws and regulations, strengthen the protection of copyright, patent, trademark and other intellectual properties, practically protect the creation values and interests of county cultural and creative industry enterprises and form a more standard, healthy and well-organized market environment [7].

To carry forward the clustering development of county creative and cultural industry and effectively reduce the uncertainty caused by enterprises and environment

At present, there is an extremely significant tendency for clustering development of China's county cultural and creative industry. The teams based on geographical positions are not only the backer patrons of personnel engaged in cultural and creative industry in the narrow sense but also the important social reproduction bases where creativity comes into play. The co-existence and complementary relationships among various enterprises in a cluster continuously extend toward the two ends of the county cultural and creative industry chain and this is the big tendency for the clustering development of cultural and creative industry [8]. That the county cultural and creative 
industries gather in some fixed gathering areas can minimize the uncertainty caused by the trading enterprises and environment. Firstly, the fixity and long-lasting property of a gather area can help the trading enterprises in the gathering area to understand each other and continuously enhance the uncertainty of trading partners and environment. Secondly, a gathering area can conveniently provide all sorts of intermediary services, through which the county cultural and creative enterprises can obtain the information of trading enterprises. Thirdly, the brands in a gathering area can also help to reduce the uncertainty.

\section{Conclusion}

To sum up, the enhancement in the management ability of China's county cultural and creative industry can greatly alleviate the pressure on resources caused by accelerating the sustainable economic development. Besides, the integrative development of county cultural and creative industry can make the modern people to reexamine the important values of our cultural resource, and gradually explore and establish a new road of cultural development with the characteristic of benefiting the people with the cultural creative industry by virtue of the huge advantage of implementing industrialized and large-scale development with cultural resources. This is extremely beneficial for the long-term development of China's county economy.

\section{References}

[1] Qi Shuyu. Strategies for the development of Chinese cultural, Beijing: Social Sciences Academic Press, 2008. 6.

[2] Li Jingwen. Current situation, tendency and policy selection of the development of Chinese cultural industry, Coastal Enterprises and Science \& Technology, 2006 (10).

[3] Wei Pengju. Eight great characteristics of Chinese creative industry in the horizon of endogenous growth theory, Investment in Beijing, 2008 (8).

[4] Liu Yang. Brief discussion on the cultivation of professional creativity of management over cultural industry, Science-Technology Enterprise, 2011 (1).

[5] Fan Yugang. Building and perfecting the management system of cultural and creative industry during development, Hunan Social Sciences, 2012 (1).

[6] Fan Baoxiang. Approaches for the development of capital cultural and creative industry for college service in Beijing region, New Horizons, 2012 (3).

[7] Wang Guohua. Transition of social roles of cultural industry researchers, Journal of Shenzhen University (Humanity and Social Science Edition), 2012 (3).

[8] Bao Feng and Shen Bandong. Analysis on the relationship between the competitiveness evaluation and gathering level of cultural and creative industry, Contemporary Communications, 2013 (1). 